\title{
CORRESPONDENCE
}

\section{Barotrauma and COVID-19}

\author{
Ken Hillman* ${ }^{*}$
}

() 2022 Crown

The evidence of the extra-alveolar air (EAA) described in a recent publication in Intensive Care Medicine [1] is explained in an important publication by Macklin and Macklin in the 1940s [2]. Over many years, they applied increasing pressure to anaesthetised cats and carefully dissected them. Initially, the air bursts the alveoli and forms small bubbles which move into the adventitia of the venules and arterioles. The air forms pulmonary interstitial emphysema, which initially moves to form mediastinal emphysema. From there, with increasing pressure, the EAA initially forms subcutaneous emphysema, then pneumothoraces directly from the air under pressure in the mediastinum, not as commonly thought, from blebs on the surface of the lungs. With further pressure, the EAA moves along the large vessels into the retroperitoneum to form pneumoretroperitoneum. This explains the air in the case report [1]. When large pressures are applied to the lungs, the EAA can also form pneumoperitoneum. Bursting of the alveoli can occur because of high inspiratory pressure, hyperexpansion or direct damage to the alveoli. Understanding the origin of EAA when lungs are exposed to high pressures and/or volumes is the key to one of the most important advances in intensive care medicine, the universal application of low tidal volumes and limited inspiratory pressures.

This report does not include any evidence of EAA before ventilation. However, we have seen several cases of patients affected by coronavirus disease 2019 (COVID-19) with massive amounts of EAA, even before the application of pressure to the lungs, suggesting the viral illness causes severe direct damage and EAA, then spreading as described [2]. The authors postulate possible barotrauma, although they were presumably not using abnormally high inspiratory pressures or large tidal volumes. The possibility of direct alveolar damage causing the EAA has important implications, including further damage caused when applying pressure to these lungs, exacerbating destruction of the lungs and causing further EAA. Consideration could be given to using high levels of inspired oxygen only or, depending on the context, even early extra-corporeal membrane oxygenation, to prevent further lung damage. The presence of extensive EAA, even without applied positive pressure indicates significant lung destruction and is a possible poor prognostic sign for short-term mortality and for long-term recovery.

\section{Declarations}

Conflict of interest

The authors declare that they have no conflicts of interest.

\section{Publisher's Note}

Springer Nature remains neutral with regard to jurisdictional claims in published maps and institutional affiliations.

Accepted: 13 January 2022

Published online: 28 January 2022

\section{References}

1. Singh A, Soni KD, Venkateswaren V, Trikha A (2022) Paranephric air in COVID-ARDS patient: an extension of pneumothorax. Intensive Care Med 48:118. https://doi.org/10.1007/s00134-021-06511-1

2. Macklin MT, Macklin CC (1944) Malignant interstitial emphysema of the lungs and mediastinum as an important occult complication in many respiratory diseases and other conditions. Medicine 23(4):281-358

\footnotetext{
*Correspondence: k.hillman@unsw.edu.au

The Simpson Centre for Health Services Research, University of New South Wales, Ingham Institute for Applied Medical Research, Sydney, Australia
}

\section{基 Springer}

